\title{
SECTORAL CO-INTEGRATION AND THE ROLE OF AGRICULTURE IN BANGLADESH
}

\author{
Mohammad Ismail Hossain*, Mst. Esmat Ara Begum*, \\ Eleni Papadopoulou** and AnastasiosSemos***
}

\begin{abstract}
This study estimates a Vector Error Correction Model (VECM) that incorporates the linkages among the agriculture, industry, construction, transport, storage and communication and service sectors for Bangladesh by using historical data from 1979 to 2009. Two cointegrating vectors confirm that all the different sectors moved together over the sample period, and therefore that their growth rates are interdependent. The long-run relationships of the industrial, construction, transport, storage and communication and service sectors to the agricultural sector were established, and the results show that the industrial and construction sectors contribute positively to the agricultural sector, the growing service sector contributes negatively and the transport, storage and communication sector shows mixed results. In addition, weak exogeneity for the agricultural sector is rejected and this underlines the fact that the agricultural sector should be considered by policymakers in any analysis of inter sector growth.
\end{abstract}

Key words: Economic growth, agriculture, inter-sectoral growth linkages and cointegration analysis.

JEL classifications: $\mathrm{C} 22,32, \mathrm{O} 13,41, \mathrm{P} 20$

Submission Date: 05/09/2012 Revision Date: 24/12/2012 Acceptance Date: 30/12/2012

* Ph.D candidate, Department of Agricultural Economics, School of Agriculture, Aristotle University of Thessaloniki, Greece. E-mail: mhossain@agro.auth.gr

** Assistant Professor, Department of Spatial Planning and Development, School of Engineering, Aristotle University of Thessaloniki, Greece. E-mail: papa@agro.auth.gr

*** Professor, Department of Agricultural Economics, School of Agriculture, Aristotle University of Thessaloniki, Greece. E-mail: semos@agro.auth.gr 


\section{INTRODUCTION}

Agriculture plays an important role in contributing to overall economic development both in developed and developing countries (Johnston, 1970). It is the primary source for employment, livelihood, calorie intake, and food security for the majority of rural households in the developing world, and especially in Bangladesh. The contribution of agricultural growth to economic development varies markedly from country to country and from one time period to another within the same country. In an industrialized country where agriculture makes a very small contribution in GDP, in such cases, the role of agriculture may not be important. But in a developing economy like Bangladesh where agriculture is usually a major production sector and accounts for a large share of GDP, in that case, the role is crucial. Furthermore, over time, within the same country the contribution of agriculture to economic development tends to change. When the economy is predominantly agrarian, agriculture has a relatively more important place. As the economy grows, the share of agricultural output in GDP and the share of rural population in total population tend to decline gradually over time. Consequently, the contribution of agriculture to the national economy declines. Despite the declining trend of agricultural share in the GDP, it will remain an important sector to the country in terms of export earning, employment and food security.

Historically, Bangladesh has followed a mixed economic model with close state control. The government's economic policies had limited success during the early years of independence. After independence in 1971, poor economic conditions in the war-ravaged country caused considerable instability, and agricultural production fell brutally. Due to political unrest and the change in government through the military coup in 1975, the economic growth of the country was low. However, over the past decade, evidence suggests that Bangladesh's economic performance has been one of the strongest in the South Asian region, reflecting gradual but continuous structural reforms, prudent macroeconomic policies and well-targeted social policies. Real growth averaged 5.5 percent in the 2000s, and inflation is slowing (Mujeri et al., 2009).

The Bangladesh economy has been diversified and is now less vulnerable than in the past to external shocks such as climate hazards, cyclones and other natural disasters. The manufacturing sector accounted for more than 63 percent of industrial production, about 30 percent of the working population and 20 percent of gross domestic product (GDP) in 2010. The services sector represents about 50 percent of GDP and 43 percent of the working population. It has expanded significantly in the past few years and has driven up growth of the Bangladesh economy (Bangladesh Economic Review, 2011). 
Despite the change and diversification observed in the Bangladesh economy (industrialization and growth of service sector), the agricultural sector remains economically and socially important for its contribution to the achievement of national objectives as regards to food security, employment and social cohesion. As a government policy objective, Bangladesh needs to boost up agriculture, to continue employment generation and earn export earnings. In fact, the agricultural sector generates around 20 percent of total Gross Domestic Product (GDP), employs 43 percent of the total labour force and agro-food exports represent around 4 percent of total exports (BBS, 2010).

In spite of the high importance placed on the agricultural sector in the Bangladesh economy, the issue of the agricultural sector's contribution to economic growth has often been raised by policy makers but rarely examined empirically. To address that issue, this paper investigates the role of the agricultural sector role in the Bangladesh economic development process and the causal link between GDP growth of the agricultural sector and other non-agricultural sectors in Bangladesh. The paper uses Johansen's multivariate approach to study the co-integration of the different sectors of the Bangladesh economy and so overcome the problem of spurious regression. Special attention is paid to both short and long run dynamic causal relationships between the agricultural and other economic sectors.

Several earlier studies have outlined the theoretical relationship between agriculture and economic growth, disagreements still persist and the causal dynamics between agriculture and economic growth is an empirical question worthy of further investigation, as described by Awokuse (2009).

Gardner (2003) studied a cross-sectional panel of 52 developing countries and found no significant evidence of agriculture leading overall economic growth. However, Tiffin and Irz (2006), using a cointegration framework and Granger-causality tests on data for 85 countries, found statistical evidence that supports the conclusion that agricultural value added is the causal variable in developing countries, while the direction of causality in developed countries is unclear.

Yao (1996 and 2000) demonstrated how agriculture has contributed to China's economic development using both empirical data and a cointegration analysis. Two important conclusions were: although agriculture's share in GDP declined sharply over time, it is still an important force for the growth of other sectors; and the growth of non-agricultural sectors had little effect on agricultural growth. This was largely due to government policies biased against agriculture and restriction on rural-urban migration.

Kanwar (2000) investigated the cointegration of the different sectors of the Indian economy (namely, agriculture, manufacturing industry, construction, infrastructure, and services) in a vector autoregressive (VAR) framework. He showed that the agriculture, 
infrastructure, and service sectors significantly affect the process of income generation in the manufacturing and construction sectors, but the reverse has not been true. Blunch and Verner (2006) found empirical evidence to support a large degree of interdependence in long-run sectoral growth in Cote d'Ivoire, Ghana, and Zimbabwe, and concluded that the sectors grow together or there are externalities or spillovers between sectors.

All the aforementioned studies have made useful contribution to understanding the potential contribution of agriculture to economic growth and the causal link between agriculture and economic growth. However, there is a significant gap in the growth literature because most of the inter-sectoral linkage studies were conducted for the developed countries. In an attempt to fill the gap in the literature, this study focuses on how the agricultural sector has been inter-related to the rest of the economy in Bangladesh.

\section{DATA AND UNIT ROOT TESTS}

Time series data of GDP indices in constant prices of the five sectors over 1979 to 2009 (Planning Commission, 2011) are used in setting up the VAR models. For easy notation, the sectoral GDP indices are denoted by: AGR for agriculture, IND for industry, CON for construction, TSC for transportation, storage and communication and SER for services. All variables are in constant taka (1994) and transformed in logarithms so that they can be interpreted in growth terms after taking first difference. The dataset consists of 31 observations. The number of observations is small for cointegration analysis but the data provide the longest possible time series for the Bangladesh economy. Before a VAR model is estimated, the data must be tested for orders of integration.

Figures 1 and 2 show that the five selected variables tend to move together over time and long run or cointegrating relationships are likely to be present in this case. 
Volume 10, Number 3, December 2012, pp105 112

\section{Figure 1.}

Trends of the indexed series against time from 1979 to 2009

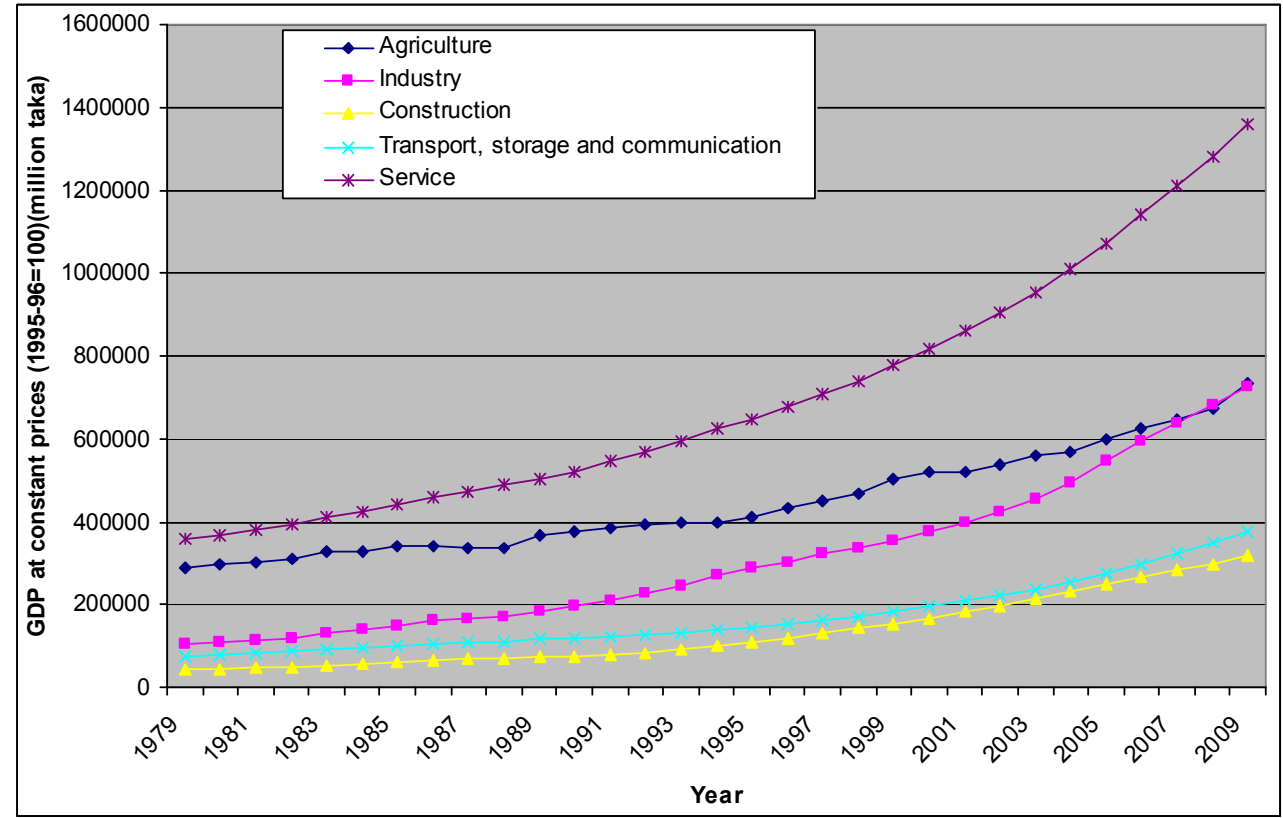

Figure 2.

Plots of (the logs of) variables AGR, IND, CON, TSC and SER against time in levels.

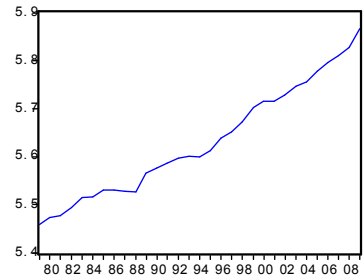

LAGR

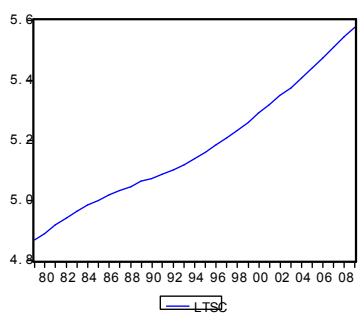

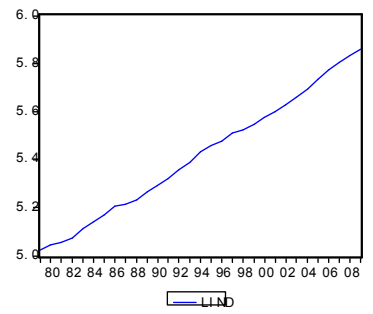

$-\angle \mathrm{Ab}$

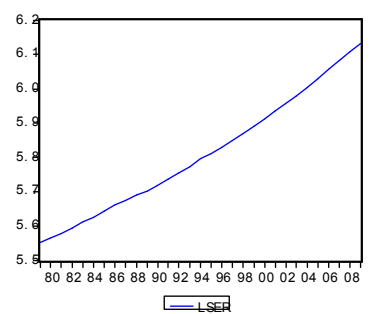

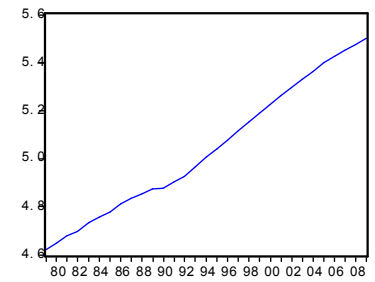

$-L \infty N_{N}$ 
Let xjt denote the logarithm GDP index for sector $\mathrm{j}(\mathrm{j}=\mathrm{AGR}, \mathrm{IND}, \mathrm{CON}$, TSC and SER) and assume (Yao 1994, 1996 and 2000) that xjt follows a third-order autoregressive process, an autoregressive model is then specified in Equation 1:

$$
\begin{aligned}
& x_{j t}=\beta_{1} x_{j t-1}+\beta_{2} x_{j t-2}+\beta_{3} x_{j t-3}+v_{j t}, \\
& \text { or } \\
& \Delta x_{j t}=\beta^{*} x_{j t-1}+\beta_{1}^{*} \Delta x_{j t-1}+\beta_{2}^{*} \Delta x_{j t-2}+v_{j t} \\
& v_{j t}: I I D\left(0, \sigma^{2}\right) \\
& \beta^{*}=\left(\beta_{1}+\beta_{2}+\beta_{3}\right)-1 \\
& \text { If } \beta^{*}=0 \text { (null hypothesis), xjtisnon-stationary. }
\end{aligned}
$$

The number of lagged terms on the right hand side can vary but the principle is to make the residual term ujt a real white noise. As Equation 1 contains two lagged terms of the first difference, the augmented Dickey Fuller (ADF) $(1979,1981)$ test can be conducted. If the variable is stationary (no unit root), the ADF test should indicate that $\beta^{*}$ is significantly smaller than zero. In estimation, each model includes a time trend and an intercept. It is obvious from Table 1 that the first differences DAGR, DIND, DCON, DTSC, and DSER are I(0), and that AGR, IND, CON, TSC and SER are I(1) which indicates that all the five variables failed to reject the unit root hypothesis at levels and rejected at the first differences.

\section{Table 1.}

Augmented Dickey-Fuller (ADF) test for unit roots ( $\tau$-ADF values)

\begin{tabular}{l|l|l}
\hline \multirow{2}{*}{ Variables } & \multicolumn{2}{|c}{} \\
\cline { 2 - 3 } & $\begin{array}{l}\text { Sectoral national } \\
\text { income indices in logs }\end{array}$ & $\begin{array}{l}\text { First differences of } \\
\text { sectoral national } \\
\text { income indices in logs }\end{array}$ \\
\hline AGR: Real GDP of agricultural sector & -0.745 & $-4.786^{* * *}$ \\
\hline IND: Real GDP of industrial sector & -2.184 & $-4.192^{* * *}$ \\
\hline CON: Real GDP of construction sector & -1.336 & $-3.332^{*}$ \\
\hline $\begin{array}{l}\text { TSC: Real GDP of transport, storage and } \\
\text { COmmunication sector }\end{array}$ & 1.967 & $-3.232^{\star}$ \\
\hline SER: Real GDP of service sector & 1.291 & $-4.388^{* * *}$ \\
\hline
\end{tabular}


Volume 10, Number 3, December 2012, pp105 112

Notes: The critical values of $\tau$-ADF: $10 \%=-3.217,5 \%=-3.567,1 \%=-4.295 . *$, ** and ***denote rejection (of non-stationarity) at $10 \%, 5 \%$ and $1 \%$ significant levels respectively.

The summary statistics of the sectoral GDP indices in logarithms and their first differences are presented in Table 2. It is interesting to note that agriculture has a strong correlation with the rest of the economy in level terms but not in the first difference. As the GDP indices are found to be I(1), it is the relationship between the first differences that is of importance and relevance. Without doing any cointegration analysis, the correlation matrix at the lower panel of Table 2 provides some interesting information. First, industry, transportation storage and communication, and services appear to be moderately and positively correlated. Second, agriculture seems to go its own way, with a weak and positive relationship with industry, transport storage and communication and services but a weak and negative relationship with construction.

Table 2.

Summary statistics of sectoral national income indices (1979-2009)

\begin{tabular}{l|c|c|c|c|c}
\hline Levels & \multicolumn{1}{l|}{ AGR } & \multicolumn{1}{l|}{ IND } & CON & \multicolumn{1}{l|}{ TSC } & SER \\
\hline Mean & 5.632 & 5.420 & 5.041 & 5.180 & 5.811 \\
\hline Standard deviation & 0.117 & 0.256 & 0.275 & 0.203 & 0.174 \\
\hline Correlation matrix & & & & & \\
\hline AGR & 1.000 & & & & \\
\hline IND & 0.991 & 1.000 & & & \\
\hline CON & 0.993 & 0.996 & 1.000 & & \\
\hline TSC & 0.995 & 0.991 & 0.994 & 1.000 & \\
\hline SER & 0.996 & 0.997 & 0.997 & 0.997 & 1.000 \\
\hline First differences & $\Delta$ AGR & $\Delta$ IND & $\Delta$ CON & $\Delta$ TSC & $\Delta$ SER \\
\hline Mean & 0.013 & 0.027 & 0.029 & 0.023 & 0.019 \\
\hline Standard deviation & 0.010 & 0.008 & 0.008 & 0.007 & 0.004 \\
\hline Correlation matrix & & & & & \\
\hline$\Delta$ AGR & 1.000 & & & & \\
\hline$\Delta$ IND & 0.138 & 1.000 & & & \\
\hline$\Delta$ CON & -0.003 & 0.269 & 1.000 & & \\
\hline$\Delta$ TSC & 0.357 & 0.202 & 0.435 & 1.000 & \\
\hline$\Delta$ SER & 0.273 & 0.496 & 0.333 & 0.694 & 1.000 \\
\hline
\end{tabular}

\section{LONG RUN RELATIONSHIPS: JOHANSEN METHODOLOGY}

Johansen and Juselius (1992) developed a procedure to estimate a co-integrated system involving two or more variables. This procedure is independent of the choices 
of the endogenous variables, and it allows researchers to estimate and test for the existence of more than one cointegrating vectors in the multivariate system. It also provides a methodology that allows the researcher to distinguish between the short and the long run relationship. The general VAR model specification is shown in equation (2).

$$
\Delta Y_{t}=\prod Y_{t-p}+\sum_{i=1}^{p-1} \Gamma_{i} \Delta Y_{t-1}+\mu D_{i}+\varepsilon_{t}
$$

where Yt is the column vector of the current values of all the variables in the system (integrated of order one), Dt is a matrix of deterministic variables such as an intercept and time trend, $\varepsilon t$ is the vector of errors are assumed $E(\varepsilon t \varepsilon t$ ) for all $t ; \Gamma$, $\Pi$, and $\mu$ are the parameters matrices. The $\mathrm{p}$ is the number of lag periods included in this model, which is determined by using the Akaike Information Criterion (AIC) and Schwartz Bayesian Criterion (BIC). The first term in equation 2 captures the long-run effects on the regressors and the second term captures the short-run impact.

In the long run, the parameter matrix $\Pi$ will be of order $n x n$, with a maximum possible rank of $\mathrm{n}$. Then, using the Granger representation theorem (Engel and Granger, 1987), the rank of $\Pi$ is found to be $r<n$, the matrix $\Pi$ may be factored as $\alpha \beta$ where $\alpha$ and $\beta$ are both of order $n \times$ r. Matrix $\beta$ is such that $\beta Y$ is $\mathrm{I}(0)$ even though $\mathrm{Yt}$ itself is $\mathrm{I}(1)$. In other words, it is the cointegrating matrix describing the long-run relationships in the model. The weighted matrix, $\alpha$, gives us the speed of adjustment of specific variables on account of deviations from the long-run relationship. The cointegration rank is usually tested by using the maximum eigenvalue and trace statistics proposed by Johansen (1988). The long-run information of the series were taken into account in analyzing the short-run sectoral growth and the resulting model is a short-run error correction model.

The number of distinct cointegrating vectors can be obtained by checking the significance of the characteristic roots of $\Pi$. This means that the rank of $\Pi$ matrix is equal to the number of its characteristic roots that differ from zero. The test for the number of characteristics roots that are insignificantly different from unity are shown in equation (3) and equation (4).

$$
\begin{aligned}
& \lambda_{\text {trace }}(r)=-T \sum_{i=r+1}^{n} \ln \left(1-\hat{\lambda}_{i}\right) \\
& \lambda_{\text {max }}(r, r+1)=-T \sum_{i=r+1}^{n} \ln \left(1-\hat{\lambda}_{r+1}\right)
\end{aligned}
$$


where $\chi$ is the estimated values of the characteristic roots (called eigenvalues) obtained from the estimated $\lambda$ matrix and $\mathrm{T}$ is the number of usable observations. Equation (3) is called the trace test, and tests the hypothesis that there are at most $r$ cointegrating vectors. In this test, $\lambda$ trace equals zero when all $\lambda \mathrm{i}$ are zero. The further the estimated characteristic roots are from zero, the more negative is and the larger the $\lambda$ trace statistic. Equation (4) is called the maximum eigenvalue test, and tests the hypothesis that there are $r$ cointegrating vectors versus the hypothesis that there are $r$ +1 cointegrating vectors. This means if the value of characteristic root is close to zero, then the $\lambda$ max will be small.

Before applying the procedure outlined above to the system, it is necessary to determine the lag length for the VAR model since the Johansen procedure is sensitive to changes in the lag structure (Maddala and Kim, 1998). Given the sample size, the optimal lag length was searched up to four lags of levels using the AIC and BIC criterions and the final prediction error. In this study, the model was estimated including two lags and an unrestricted constant and a trend component in the cointegration space. For this case, the underlying VAR model contains both intercepts and deterministic linear trends, with the intercept and the trend coefficients being unrestricted.

It is observed from Table 3, the trace tests fail to reject the null of two cointegrating vectors $(\mathrm{r}=2)$ among the five variables at the 1 percent significance level. This is because the number of cointegration vectors ( $r$ ) is equal to the number of equations $(\mathrm{n}=5)$ minus the number of roots $(\mathrm{p}=1)$ in the companion matrix. In all the following analyses, we assume the presence of two stationary or co-integrating relations and three common stochastic trends in the system. The presence of two cointegrating vectors provides evidence that there are two processes that separate the long run from the short-run responses of the Bangladesh economy. As Kanwar (2000) notes, this does not imply that some of the sectors did not outpace the others, but only that the economic forces at work functioned in such a way as to tie together these sectors in a long-run structural equilibrium, and while short-run shocks may have led deviations from this long-run path, forces existed whereby the system reverted back to it.

\section{Table 3.}

Evidence of cointegration using maximal eigenvalue and trace statistical tests for all five sectors in Bangladesh 


\begin{tabular}{|c|c|c|c|c|c|c|c|c|c|}
\hline \multicolumn{3}{|c|}{ Hypotheses } & \multirow[b]{2}{*}{$\begin{array}{l}\text { E i g e } n \\
\text { value }\end{array}$} & \multicolumn{3}{|c|}{ Maximum eigen value test } & \multicolumn{3}{|c|}{ Trace statistical test } \\
\hline $\mathrm{H}_{0}$ & $\mathrm{H}_{1}^{1}$ & $\mathrm{H}_{1}^{2}$ & & $\lambda_{\max }$ & $\begin{array}{l}5 \% \\
\text { critical } \\
\text { value }\end{array}$ & $\begin{array}{l}1 \% \\
\text { critical } \\
\text { value }\end{array}$ & $\lambda_{\text {trace }}$ & $\begin{array}{l}5 \% \\
\text { critical } \\
\text { value }\end{array}$ & $\begin{array}{c}1 \% \\
\text { critical } \\
\text { value }\end{array}$ \\
\hline$r=0$ & $r=1$ & $r \leq 1$ & 0.856 & $56.17^{\star \star}$ & 37.52 & 42.36 & $130.46^{* \star}$ & 87.31 & 96.58 \\
\hline$r=1$ & $r=2$ & $r \leq 2$ & 0.720 & $36.91^{\star \star}$ & 31.46 & 36.65 & $74.29 * \star$ & 62.99 & 70.05 \\
\hline$r=2$ & $r=3$ & $r \leq 3$ & 0.453 & 17.53 & 25.54 & 30.34 & 37.38 & 42.44 & 48.45 \\
\hline$r=3$ & $r=4$ & $r \leq 4$ & 0.357 & 12.79 & 18.96 & 23.65 & 19.85 & 25.32 & 30.45 \\
\hline$r=4$ & $r=5$ & $r \leq 5$ & 0.216 & 7.06 & 12.25 & 16.26 & 7.06 & 12.25 & 16.26 \\
\hline
\end{tabular}

** denotes reject the null hypothesis at $1 \%$ level of significance. 1, 2 denote alternative hypothesis for maximum eigenvalue and trace statistical tests, respectively

Various model evaluation diagnostic tests for the residuals are presented in Table 4. All the statistics indicate that the residuals are Gaussian without any strong evidence of autocorrelation and heteroskedasticity. The residual plots and distributions are shown in Figure 3.

Table 4.

Model diagnostics (a time trend in the cointegration space)

\begin{tabular}{c|c|c|c|c|c}
\hline Components & AGR & IND & CON & TSC & SER \\
\hline$\sigma$ & 0.007 & 0.006 & 0.005 & 0.002 & 0.001 \\
\hline $\begin{array}{c}\text { Jargue-Bera } \\
\text { (normality) }\end{array}$ & 0.383 & 0.159 & 0.099 & $4.595^{\star}$ & 1.857 \\
\hline$F_{\text {arch }}$ & 1.845 & 3.663 & 0.276 & 3.497 & 0.200 \\
\hline$F_{\text {het }}$ & 2.285 & 0.828 & 0.837 & 1.102 & 1.269 \\
\hline
\end{tabular}

*denotes rejection at the $5 \%$ significance level. 
Volume 10, Number 3, December 2012, pp105 112

Figure 3 .

Residual plots and distributions
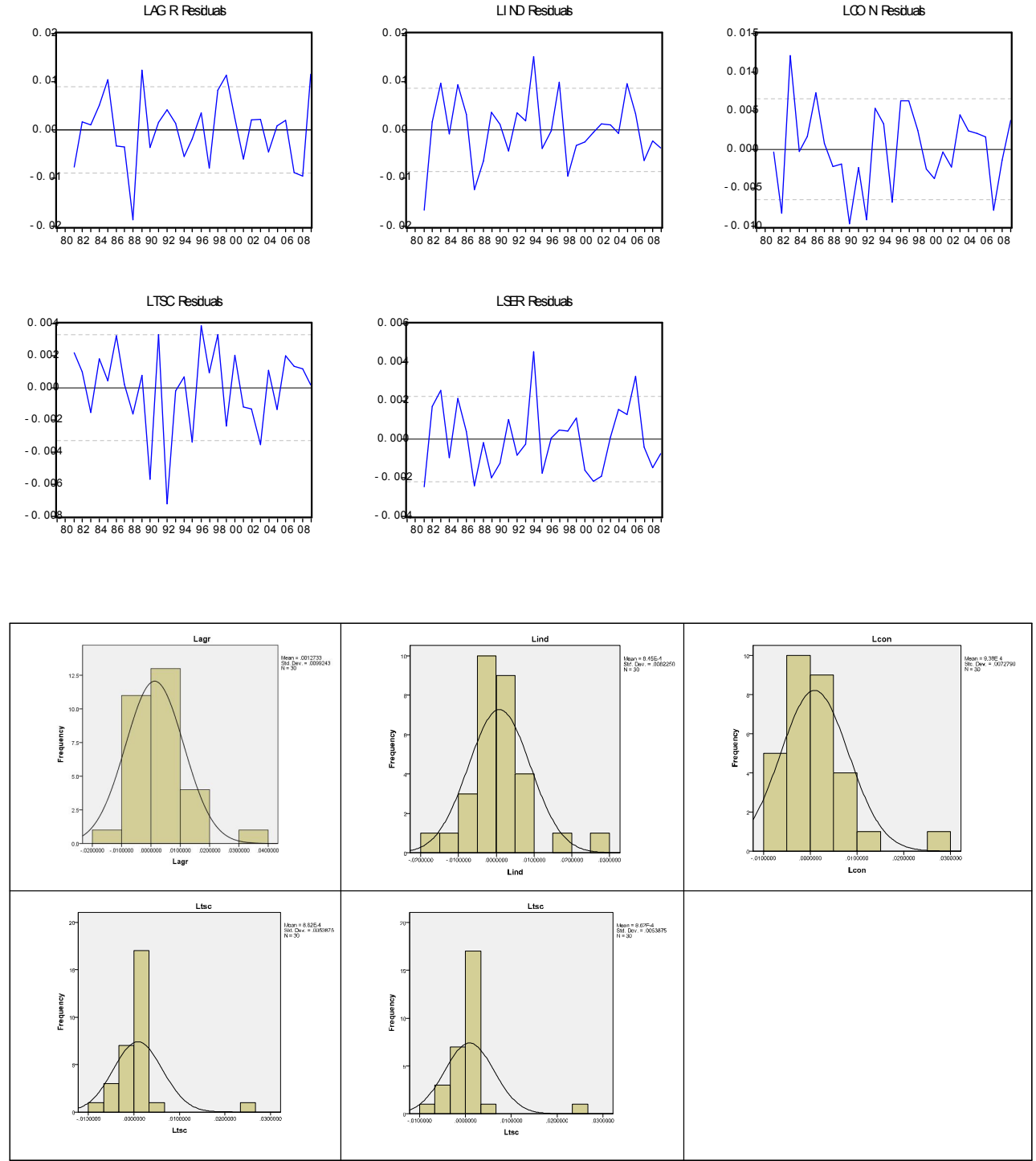
As the models have passed various statistical tests, the next step is to derive the $\mathrm{a}$ and $\mathrm{b}$ matrices within the $\Pi$ and conduct a hypothesis test for weak exogeneity. The following long run relationships, $\Pi$ are identified by imposing a restriction that there are two contegration vectors (Table 5):

\section{Table 5.}

Represents the long run relationships, П matrix

$$
\left[\begin{array}{l}
\Delta A G R_{t} \\
\Delta I N D_{t} \\
\Delta C O N_{t} \\
\Delta T S C_{t} \\
\Delta S E R_{t}
\end{array}\right]=\left[\begin{array}{ccccc}
0.644 & 0.076 & 0.003 & -0.013 & 0.065 \\
-0.423 & 0.964 & -0.145 & -0.354 & 0.009 \\
-0.442 & -0.170 & 0.968 & 0.042 & -0.037 \\
0.571 & -0.754 & -0.427 & 0.944 & 0.026 \\
1.140 & 1.826 & 1.965 & 1.643 & 0.942
\end{array}\right]\left[\begin{array}{l}
A G R_{t-1} \\
I N D_{t-1} \\
C O N_{t-1} \\
T S C_{t-1} \\
S E R_{t-1}
\end{array}\right]
$$

By imposing a restriction that there are two cointegration vectors, the long run estimates $\beta$ and the adjustment coefficients, $\alpha$ are presented in Table 6 .

\section{Table 6.}

The estimated long run estimate $(\beta)$ and speed of adjustment coefficients $(\alpha)$

$$
\begin{aligned}
& \beta=\left[\left(\begin{array}{lllrl}
1.00 & 0.00 & 1.896 & -5.056 & 7.601 \\
0.00 & 1.00 & -1.671 & 5.117 & -9.119
\end{array}\right)\left(\begin{array}{l}
\operatorname{LAGR}_{t-1} \\
\operatorname{LIND}_{t-1} \\
L_{C O N_{t-1}} \\
L_{S S C_{t-1}} \\
\operatorname{SER}_{t-1}
\end{array}\right)+\left(\begin{array}{c}
-0.231 \\
0.191
\end{array}\right) \text { TREND }_{t-1}\right] \\
& \alpha=\left(\begin{array}{cc}
0.451 & 0.149 \\
(1.312) & (0.486) \\
0.419 & 0.317 \\
(1.552) & (1.191) \\
0.258 & 0.338 \\
(0.867) & (1.185) \\
-0.230 & 0.356 \\
(-1.369) & (2.307) \\
-0.135 & -0.503 \\
(-0.533) & (-1.716)
\end{array}\right)
\end{aligned}
$$


From the Table 6 the stable long run equilibrium equations can be written as:

$$
\begin{aligned}
& A G R=0.419 I N D+0.258 C O N-0.230 T S C-0.135 S E R \\
& A G R=0.317 I N D+0.338 C O N+0.356 T S C-0.503 S E R
\end{aligned}
$$

The results shows that the agricultural sector in Bangladesh has established two long-run relationships to the industrial, construction, transport storage and communication and service sectors. The positive sign of the industrial and construction sectors in both relationships suggests that there exists a strong positive relationship to the agricultural sector. This implies that an increase in the industrial and construction sectors will affect the agricultural sector positively, holding all other variables that affect the agricultural sector constant.

It is observed from the empirical analysis that the service sector negatively contributed to the agricultural sector. This indicates that the service sector has reached a higher level of economic progress. At early stages of development, the service sector is able to stimulate growth of the agriculture and manufacturing sectors and, therefore, a positive relationship is expected. However, in more matured economies, resources such land, labor and capital will be transferred to the service sector as a result of higher income elasticities for services compared to the manufacturing and agricultural products.

\section{GRANGER NON-CAUSALITY}

Since cointegration relationships were found between the variables, we next investigate the direction of causality by estimating a VECM derived from the long-run cointegrating relationship (Engle and Granger, 1987; Granger, 1988). Table 7 shows the result of non-causality tests.

The results provide support for causality running from construction to agriculture. Support for reverse causality is not found in the short run and growth of AGR does not generate any significant effects on the CON sector. In Bangladesh, the construction, electricity, energy and water supply sub-sectors tend to depend on budgetary allocations rather than directly on impulses emanating from the growth of the agricultural sector. This unidirectional causality running from $\mathrm{CON}$ to growth in the agricultural sector may indicate that agriculture in Bangladesh is an energy and water-dependent sector which also support of the nature of the country's economy where most of the irrigated areas are covered by the ground water sources. Since the Bangladesh government still 
subsidizes an important percentage of the fuel and electricity prices for the farmers and rural people, policymakers should be mindful that energy conservation reforms should be gradually implemented, in order to not adversely impact the productivity and growth of the agricultural sector in the short run.

Also, the statistical results provide some support for only unidirectional causality in the short-run running from IND to AGR. This evidence may not be taken to imply that productivity gains in agriculture (where they lead to cheaper inputs) feed back into the agro-food industry. Moreover, an increased demand from Bangladesh farmers for inputs (such as farm machinery and equipment, including tractors, replacement parts, irrigation equipment, and pumps), may not stimulate the Bangladesh manufacturing industry through backward linkages.

In addition, when examining the linkage between AGR output and TSC output the results provide support for unidirectional causal relationship in the short-run running from TSC to AGR. This result indicate that the transport, storage and communication sector plays an important role to boost up agriculture sector as agriculture produces goes to the final usages through the process of this sectoral activities.

Finally, the results show strong evidence for bidirectional relationship in the short run between AGR to SER. This result supports the view that AGR and SER are related with each other in the short run.

\section{Table 7.}

Results of non causality tests between agriculture and non agricultures sectors

\begin{tabular}{|c|c|}
\hline Hypothesis of non-causality & Short run Granger non-causality \\
\hline $\mathrm{H}_{0}:$ LAGR does not Granger Cause IND & 0.396 \\
\hline $\mathrm{H}_{0}:$ LND does not Granger Cause LAGR & $3.854^{*}$ \\
\hline $\mathrm{H}_{0}$ :LAGR does not Granger Cause LCON & 0.435 \\
\hline $\mathrm{H}_{0}:$ LCON does not Granger Cause LAGR & $4.797^{*}$ \\
\hline Ho: LAGR does not Granger Cause LTSC & 0.837 \\
\hline Ho: LTSC does not Granger Cause LAGR & $4.053^{*}$ \\
\hline $\mathrm{H}_{0}:$ LAGR does not Granger Cause LSER & $2.773^{\star *}$ \\
\hline $\mathrm{H}_{0}$ :LSER does not Granger Cause LAGR & $4.268^{*}$ \\
\hline
\end{tabular}

$*$ and ** Rejection of hypotheses $\mathrm{H} 0$ at $5 \%$ and $10 \%$ levels of significance respectively. 


\section{CONCLUSION}

This study estimates an econometric model that incorporates the linkages among the broad sectors (agriculture, industry, construction, transport, storage and communication, and service) of the Bangladesh economy using a Vector Error Correction Model (VECM). This procedure is employed to identify the existence of long-run and short-run relationships among different sectors in the economy. The empirical findings from the analysis confirm that the different sectors in the Bangladesh economy moved together over the sample period, and for this reason their growth was interdependent. This implies that once the sectors deviate from the stable, long-run path the sectors have the tendency to return to the long-run equilibrium.

Our analysis shows two long-run cointegrating relationships for the economy of Bangladesh. The long-run relationship of the agricultural sector to other sectors shows that the industrial sector plays a positive role on the agricultural sector. However, the growing service sectors seem to be detrimental to the growth of the agricultural sector. This is an indication for that Bangladesh economy is progressing at a higher level of economic development and facing resource constraints.

The results of non-causality tests indicate that the agricultural sector seems to have a partial role in the short run as a driving force in the growth of other non-agricultural sectors of the Bangladesh economy and growth of agricultural output may be conducive only to the agro-food industry sub-sector in the short run. This may be the result of the relative decrease of the role that the agricultural sector plays as provider of inputs for the Bangladesh industry and the consequence of the traditional Bangladesh export strategy with low value-added products. Accordingly, the role of policymakers should be to stimulate the commercialization possibilities and support the private sector effort.

Also, the results of the causality analysis indicate that the agricultural sector in Bangladesh is energy and water-dependent and any shortage in energy and water supply may adversely affect the growth of the agricultural sector in the short run. Furthermore, since the Bangladesh government still subsidizes an important percentage of the fuel and electricity prices, policymakers should be mindful that energy conservation measures should be implemented gradually in order to not adversely affect the productivity and growth of the agricultural sector in the short run. In addition, while Bangladesh started improving the quality of services, our statistical results indicate that the agricultural sector still does not fully benefit from the development of the commerce and services sector and presence of constraints continue to hamper growth of agricultural output and productivity in Bangladesh. 
To support government investments in agriculture, policymakers should be more mindful that the improvement of private initiative in the agricultural sector requires more facilitation. 


\section{REFERENCES}

Awokuse, T.O. 2009. Does agriculture really matter for economic growth in developing countries? Paper presented at the American Agricultural Economics Association Annual Meeting, Milwaukee, WI, July 26-28.

Bangladesh Bureau of Statistics. 2010. Statistical Yearbook of Bangladesh. Statistics Division, Dhaka: Ministry of Planning.

Bangladesh Economic Review. 2011. Ministry of Finance, Government of the Peoples' Republic of Bangladesh. Dhaka, Bangladesh. Working paper series no. WP 0901, Policy analysis unit, Bangladesh Bank.

Blunch, N.H., and D. Verner. 2006. Shared sectoral growth versus the dual economy model: Evidence from Cote d'Ivoire, Ghana, and Zimbabwe. Journal Compilation, African Development Bank.

Dickey, D. A. and W. A. Fuller. 1979. Distribution of the estimators for autoregressive time series with a unit root. Journal of the American Statistical Association 74: 427-431.

Dickey, D. A. and W. A. Fuller. 1981. Likelihood ratio statistics for autoregressive time series with a unit root. Econometrica 49 (4): 1057-1072.

Engel, R. E. and C.W. J. Granger. 1987. Cointegration and error correction: representation, estimation and testing. Econometrica 55: 251-76.

Gardner, B. 2003. Causes of rural economic development. Paper presented at the 25th International Conference of Agricultural Economists, Durban, August 16-22.

Granger, C.W.J. 1988. Developments in a concept of causality. Journal of Econometrics 39: $199-211$.

Johansen, S. 1988. Statistics analysis of cointegration vectors. Journal of Economic Dynamics and Control 12: 231-254.

Johansen, S. and K. Juselius. 1992. Testing structural hypotheses in a multivariate cointegration analysis of the PPP and the UIP for UK. Journal of Econometrics 53: 211-244.

Johnston, B.F. 1970. Agriculture and structural transformation in developing countries: a survey of research. Journal of Economic Literature 8: 369-404.

Kanwar, S. 2000. Does the dog wag the tail or the tail the dog? Cointegration of Indian agriculture with non-agriculture. Journal of Policy Modeling 22 (5): 533-56.

Maddala, G.S. and Kim, I.M. 1998. Unit roots, cointegration, and structural change. Cambridge University Press, Cambridge.

Mujeri, M.K., M. Shahiduzzaman and M.E. Islam. 2009. Measuring inflationary pressure in Bangladesh: the P-star approach.

Planning Commission. 2011. Sixth five year pan FY2011-FY2015: accelerating growth 
and reducing poverty (part 3, statistical annex and technical framework). Ministry of Planning, Government of the Peoples' Republic of Bangladesh. Dhaka, Bangladesh.

Tiffin, R. and Irz, X. 2006. Is agriculture the engine of growth? Agricultural Economics 35 (1): 79-89.

Yao, S. 1994. Cointegration analysis of agriculture and non-agricultural sectors in the Chinese economy 1952-92. Applied Economics Letters 1: 227-229.

Yao, S. 1996. Sectoral conintegration, structural break and agriculture's role in the Chinese economy in 1952-92: a VAR approach. Applied Economics 28: 1269-1279.

Yao, S. 2000. How important is agriculture in China's economic growth? Oxford Development Studies 28 (1): 33-49. 